\title{
3 Researc Square

\section{Knowledge, attitude and practice of Sri Lankan women towards breast cancer: A cross sectional study}

\section{N.D. Ranaweera}

General Sir John Kotelawala Defence University

P.M.C. Dinesha

General Sir John Kotelawala Defence University

C.A.K. Pathirage

General Sir John Kotelawala Defence University

P.W.D.N. Weerasinghe

General Sir John Kotelawala Defence University

D.M.K.N. Senarathna

General Sir John Kotelawala Defence University

G.A.G.M.S. Ariyasena

General Sir John Kotelawala Defence University

G.L.S.Galgamuwa ( $\square$ lahiruahs@yahoo.com )

General Sir John Kotelawala Defence University

H.S.M.S.K. Wijesiri

General Sir John Kotelawala Defence University

K.A.S.J. Balawardhana

General Sir John Kotelawala Defence University

Research article

Keywords: Breast cancer, Risk factors, Early detection techniques

Posted Date: September 23rd, 2019

DOl: https://doi.org/10.21203/rs.2.14784/v1

License: (c) (i) This work is licensed under a Creative Commons Attribution 4.0 International License.

Read Full License 


\section{Abstract}

Introduction: Breast cancer is a type of cancer that develops from breast tissue. Although the knowledge on breast cancer among women in Sri Lanka is high, their practice of breast self-examination is poor. This study was aimed to determine attitudes, practices and the awareness of early detection techniques and risk factors among women in Sri Lanka.

Method: A study was conducted between two groups in National Cancer hospital, Sri Lanka and a peripheral women clinic consisting 317 participants in each group. Self-administered questionnaire was used to collect data regarding the awareness of early detection techniques, signs and symptoms and risk factors for breast cancers.

Results: A total of $33.8 \%$ of peripheral women clinic and $65.0 \%$ in National Cancer hospital patients had good knowledge regarding risk factors. The knowledge of risk factors, signs and symptoms and screening methods about breast cancers was significantly high in patients attending to National cancer hospital. Older aged people have less awareness about screening methods compared to younger people. People with high education background and those have a family history of breast cancer had more aware about screening and therapeutic methods.

Conclusion: Comparative to the peripheral women clinic, patients attending to National Cancer Hospital had a fairly good knowledge, practice and attitude regarding the early detection techniques, risk factors, signs and symptoms.

Key words : Breast cancer, Risk factors, Early detection techniques

\section{Introduction}

Breast cancer is a major public health problem in both developed and developing countries and has become the second leading cause of deaths among women worldwide [1]. Over 1.15 million women worldwide was diagnosed with breast cancer each year and more than 500,000 of them face death. Breast cancer has become the most common cancer type among women in Sri Lanka.

There is a variety of the risk factors with respect to the geographic characteristics as well as with the life style related habits of the community. The utmost weight can be spread for the risk factors like, female gender, family history of breast cancer, early menarche, late menopause, older aged in the first child birth, genetic mutation, diet, obesity, smoking and alcohol consumption [2]. Furthermore, breast feeding was found to be a protective factor against breast cancer and dietary and life style factors such as obesity, smoking and alcohol consumption and sedentary life style was identified as risk factors for breast cancers by the nutritional and epidemiological surveys $[3,4]$.

Knowledge regarding early diagnosis and screening was reported as a significant factor which determines people's screening seeking and adhering behavior. The majority of patients in developing 
countries start to diagnose breast cancers in their advanced stages due to the low level of awareness regarding early warning signs, screening techniques among general female population and poor prognosis of the patient [5].

The successfulness in the treatment as well as the early detection of breast cancer in the early stages of breast cancer depends on the early diagnosis. This could directly effect for the survival rate as well as the quality of life of the patients. Breast Self-Examination (BSE), mammography and clinical Breast Examination (CBE) are techniques that provide the best approach in the sense of reducing the risk of dying from breast cancer. Proper knowledge about early warning signs and screening methods for breast cancer plays and effective role in developing and early detection programs in the community [5].

Recent studies in Sri Lanka reported that the awareness levels about risk factors and early detection measures of breast cancer, such as CBE and BSE were predominantly in a lower level. Moreover, it has been found that late presentation of breast cancer is significant and the majority of patients with breast cancer were diagnosed at the advanced stages of the disease. Therefore, the awareness about breast cancer and early detection techniques are need urgent.

It is a vital necessity to explore the baseline values of the knowledge to prevent the occurrence of breast cancer as well as for the early detection of breast cancer. Implementation of new studies for assessing the level of knowledge regarding breast cancer in the population is important [5].

It is difficult to find a study conducted in Sri Lanka that has been comprehensively evaluated the awareness levels regarding risk factors, early warning signs, therapeutic and screening methods as well as the predictive factors that is being associated with the occurrence of the breast cancer. The current study aims at women specifically to evaluate the levels of knowledge about risk factors, early detection techniques, signs and symptoms of breast cancer and therapeutic methods of breast cancer. Ultimately to determine which women are most vulnerable for having less knowledge.

\section{Methodology}

\section{Study setting and population}

This cross-sectional study was carried out among two groups of women interested in participating at a peripheral women clinic at Piliyandala Medical officer of Health $(\mathrm{MOH})$ area and women who were diagnosed with breast cancer, who attended breast cancer clinics which were conducted at the National Cancer Hospital (NCH) in each group from January to June, 2018. Peripheral women clinics invite people to participate in a planned comprehensive cancer control program. National Cancer Hospital is the Sri Lankan main oncological institution where almost all the patients who have diagnosed with breast cancer receive treatments. For the second sample the investigators recruited patients who have already diagnosed with breast cancer with in the age range of 30-65 years. 
The Well Women clinics (WWC) are the clinics that targets on preventive healthcare of the Sri Lankan society. These clinics were conducted under the supervision of the Ministry of Health. Piliyandala $\mathrm{MOH}$ division was selected since, the estimated population in Piliyandala $\mathrm{MOH}$ area is 192,390 and the women who are eligible to participate for the WWCs are $1 \%$ of the above population. The area span is about 42 square kilometers. Piliyandala $\mathrm{MOH}$ area consists of 14 clinic centers. The study outcome is relatively can be generalized to the area since almost all 14 WWC cover up in the study.

As a part of this population based program, the women's awareness levels about different aspects of breast cancer, including risk factors, early warning signs, and therapeutic and screening approaches were evaluated. During the study period, a self-administered questionnaire was distributed among women attended to those institutions before contributing at screening and educational programs. The participants were informed about the increased incidence rate of breast cancer, particularly among the young Sri Lankan female population.

\section{Sampling method}

Five clinic areas and twenty five WWCs were randomly selected from the $\mathrm{MOH}$ area, Piliyandala. Four clinics, five wards and the chemotherapy unit were selected to collect data from the National Cancer Hospital, Sri Lanka. The whole population had fulfilled the inclusion criteria were recruited until the sample size is achieved.

Sample size was calculated using the equation of $n=z^{2} p(1-p) / d^{2}$ where $n=$ sample size, $z=1.96$; critical value of specified confidence at $95 \%$ confidence interval, $p=$ probable estimate of proportion of the prevalence for awareness about risk factors for breast cancers among females in Sri Lanka (78\%) [6]. Minimal sample size was calculated as 265 . In addition, $20 \%$ sampling error was added to minimize irresponsible and recording errors and the final sample size was 317. In order to compare the awareness of breast cancer risk factors of women who already have breast cancers and who are apparently healthy; 317 women were selected from each group.

Women aged between 30 to 65 years attended to the breast cancer clinics in national hospital and the peripheral clinic were included for this study. Women, who are less than 30 and more than 65 years, were already diagnosed with a breast cancer and physically and mentally disabled women were excluded from the study.

\section{Study Instrument and Variables Assessment}

A self-administered questionnaire was used for data collection. The questionnaire consisted of 34 questions to assess the knowledge, attitude and the practice about breast cancer risk factors and early detection techniques. The questionnaire was organized in to five sections such as socio-demographic variables, that section includes questions such as well-established risk factors, early warning signs, questions regarding early detection techniques and questions regarding the awareness and attitudes 
screening methods and negligence on population practices. Descriptively the socio-demographic questions age, education status (no formal education, less educated and university graduation/diploma), no of children, breast fed or not, family history of breast cancer were asked. Secondly well established risk factors that influence for the breast cancers were evaluated such as infertility, early age at menarche, age of menopause, breastfeeding, family history of breast cancer, being obese, smoking and alcohol consumption diet, Stress and Depression and finally consumption of Hormone Replacement of Therapy (HRT) were assessed from the sample. Thirdly the researchers included questions regarding nine established warning signs, lump in breast, redness of the breast, breast or armpit pain, discharges other than breast milk in nipple, rash on the nipple, changing the shape and the size of the breast, changing the position of nipple, and finally pulling in of the nipple. Fourthly questions were raised regarding the early detection techniques, specifically about the screening method and the practices and knowledge regarding them. This included Fine Needle Aspiration biopsy for Cytology (FNAC), CT scan, mammography, monthly breast self-examination (BSE), and biannual breast examination by a physician also known as the Clinical Breast Examination. Final section included the questions regarding the awareness and attitudes on screening methods and negligence exists among the population. There patients direct attitudes regarding the early detection techniques were assessed while linking them with the courses for negligence.

A self-administered questionnaire was formulated in Sinhala and translated into English and Tamil. All the information regarding privacy and confidentiality of the participants was provided in the information sheet. Privacy and confidentiality was ensured at all stages of the study. Participants of the $\mathrm{MOH}$ clinics were addressed after the health education session by the $\mathrm{MOH}$. Participants of National Cancer hospital were contacted at the wards, clinics and the chemotherapy unit of the Hospital. They were addressed individually whenever they were free while the ongoing treatments were providing. Once the participants were determined to be eligible to participate in the study, they were approached by the investigators to explain the process of the study.

They were explained that their participation is entirely voluntary and without any compensation. Further, the information sheet and the consent form were distributed among eligible participants and written informed consent was taken. The information sheet was kept with the participant to contact the investigators in any time if they need any clarification or any complaints regarding the study. Only the consent forms, which ensure that participants have understood the information, was collected back. Participants were informed that their absence of participation will not be affected during their treatment or any other care in the future. They were informed that they can withdraw from the study at any time, before or during the data collection process. The name of the participant was not recorded on questionnaires. The access to the collected data was only for the investigators, the co-supervisor and the supervisor of this study. The investigators will protect the confidentiality and the privacy of the participants in all the stages of the study. The questionnaire was pre-tested before using in the study at a well women clinic at the Piliyandala $\mathrm{MOH}$ area and at the National Cancer Hospital, Sri Lanka to assess the feasibility of the study and drawbacks of the questionnaire. Pre-test was done among women who fulfilled the inclusion criteria. 
The informed written consent was taken from all the participants of the study. The anonymity and confidentiality of data and privacy of the participants were properly maintained by using a serial number. Participants were fully informed regarding the participation of the study is on voluntary basis and they can leave the study on their preferences moreover participants were convinced that there will be no any negative consequences occur due to the refusal in terms of accessing their health care services. Participants' privacy and confidentiality were maintained by the researchers by adhering to a serial number system instead of using their names. The data collection process was conducted by maintaining the privacy of the participant.

\section{Statistical analysis}

Data were entered into Microsoft Excel data sheet. Collected data were coded and analyzed using the Statistical Package for Social Science (SPSS) version 23 software. A scoring system was used to analyze responses to close ended questions on knowledge. Descriptive statistical analysis was carried out awarding score of 01 for every positive answer and score of 0 for every negative answer. Open ended questions were summarized and descriptive statistics were carried out. Any participant who did not answer was considered as a negative response. A total of 10 questions were asked to assess knowledge of risk factors and 9 questions were asked about signs and symptoms. Chi square test was used to determine the significance of the awareness of risk factors and symptoms of breast cancers among two groups. $P$ value less than 0.05 was considered as significant.

\section{Results}

A total of 634 women (317 per each group) with the mean age of $28.07 \pm 8.1$ years were participated for the study. Majority of both populations have completed the secondary education, however, one fourth of participants in $\mathrm{MOH}$ clinics completed tertiary education level while only $12 \%$ of female participants of $\mathrm{NCH}$ had completed tertiary level education. More than $75 \%$ of women had breast fed to their children. Only $7.9 \%$ of $\mathrm{MOH}$ sample and $22.7 \%$ of $\mathrm{NCH}$ participants expressed that they have a family history of breast cancer (Table 1).

Table 1. Socio demographic characteristics of study participants

Knowledge among women regarding signs and symptoms was significantly higher in NCH compared to $\mathrm{MOH}$ sample. Majority of women participating to the clinics in $\mathrm{MOH}$ had no knowledge about signs and symptoms of breast cancer. Only a quarter of participant had aware of changing the size of the breast is a sign for breast cancer. In addition one third of $\mathrm{MOH}$ and half of $\mathrm{NCH}$ participants had no idea of nipple rash is a sign of breast cancer. Very low number of participants has knowledge about usage of hormone replacement therapy, start menarche at early age and less activity level are risk factors for breast cancer. Lump or thickening of the breast was the commonest known sign in both participants (Table 2).

Majority of the participants, $353(55.7 \%)$ said that they do not have any risk factor which can cause breast cancer. Most of the participants, $(67.8 \%)$ from the $\mathrm{NCH}$ admitted that they were having at least 
one risk factor.

Table 2. Awareness regarding signs and symptoms and risk factors of breast cancer

It is clearly visible that knowledge regarding methods of early detection of breast cancer among $\mathrm{NCH}$ is higher than $\mathrm{MOH}$ sample (89.9\% and $70.0 \%$ of $\mathrm{NCH}$ and $\mathrm{MOH}$ respectively).

In the present study, we identified that the knowledge of signs and symptoms and risk factors is significantly increase with education level. Young Patients have more knowledge about breast cancer compare to older people in $\mathrm{NCH}$. However, young patients in $\mathrm{MOH}$ have low awareness about risk factors (Table 3).

Table 3. Awareness of signs and symptoms and risk factors with socio demographic characteristics

The knowledge of screening methods for breast cancer is significantly higher in patients participate clinics in $\mathrm{NCH}$ than patients participating to $\mathrm{MOH}$ clinics. The most known early detection method among $\mathrm{MOH}$ participants is BSE (80.1\%) and the least known screening method is Mammography (32.8\%). Among NCH Participants, the most known and least known early detection methods are CBE $(91.8 \%)$ and Magnetic Resonance Imaging [MRI] (62.8\%) respectively (Table 4).

Table 4. The knowledge regarding screening methods

When considering socio demographic characteristics with the awareness of breast cancer screening techniques, young educated participants had higher knowledge of screening methods. In the present study, we identified that age is significantly associated with BSE $(p=0.011)$, mammography $(p=0.008)$ and with FNAC $(p=0.044)$. Older aged people have less awareness about screening methods compared to younger people. Educated people had more significantly more aware about BSE $(p<0.001), \operatorname{CSE}(p=$ $0.039)$, mammography $(p<0.001)$ and FNAC $(p=0.027)$ than people with low education background. In addition, patients who have a family history of breast cancer have significantly high awareness about mammography $(p=0.016)$ compared to people with no history of breast cancer among their family members.

According to the present study results, $\mathrm{MOH}$ and $\mathrm{NCH}$ participants practice BSE (43.5 \%) and (59.3\%) respectively. According to the following results, majority of the $\mathrm{MOH}$ sample had never done CBE (65.9 $\%)$. All participants from $\mathrm{NCH}$ had performed $\mathrm{CBE}$ before even as an investigation procedure. The most respondents didn't know the recommended age to start mammography examination, $\mathrm{MOH}(48.9 \%)$ and $\mathrm{NCH}(41.0 \%)$.

Majority of participants practiced BSE once a month in both groups. Among the two samples $47.9 \%$ of $\mathrm{MOH}$ and $39.1 \%$ of $\mathrm{NCH}$ sample knew at what age BSE should be started. According to $\mathrm{MOH}$ sample, $27.4 \%$ (87) and $\mathrm{NCH}, 29.7 \%$ (94) practiced BSE monthly. According to the present study results, $\mathrm{MOH}$ and $\mathrm{NCH}$ participants practice BSE (43.5\%) and (59.3\%) respectively. BSE had been initiated most 
between 30- 35 years in the $\mathrm{MOH}$ sample while in $\mathrm{NCH}$ it had been most after 35 years. There is significance between the level of education and the practice of BSE.

Majority of the participants in $\mathrm{MOH}$ clinics (65.2\%) had never done CBE. All participants from $\mathrm{NCH}$ had performed CBE before even as an investigation procedure. Majority of $\mathrm{MOH}(58.0 \%)$ and $\mathrm{NCH}(57.4 \%)$ samples had stated that they didn't know how often CBE should be done until 40 years. The most respondents had no idea about the recommended age to start mammography examination (Table 5).

Table 5. Practices of early detection methods for breast cancer

When studying the relationship between the level of education with the frequency of attending for CBE per year among $\mathrm{MOH}$ population, there was significance between educational level and the knowledge on BSE. However, no significance found between the family history of breast cancer with the practice of BSE.

Majority stated that they will visit a physician within a week if they have developed a breast lump. According to the study, it is clear that most women didn't have a problem regarding the doctor's gender for breast examination. In $\mathrm{MOH}$ sample (25.2\%) and $\mathrm{NCH}$ (32.5\%) believed that breast cancer occurs most common in old women. Majority of participants reported that breast cancer is a curable disease. Out of the $\mathrm{MOH}$ population (32.5\%) and $\mathrm{NCH}(34.4 \%)$ had stated that 5 years survival is rare following a breast cancer (Table 6).

Table 6. Attitudes regarding breast cancer

The most common reason for not practicing BSE was, they think that they don't have a breast problem. Most of NCH participants had stated that they didn't practice BSE due to carelessness. The most frequent reason stated in $\mathrm{MOH}$ sample was "no signs and symptoms of breast cancer" (64.6\%). In NCH all the participants had done $\mathrm{CBE}$, ever since when the patients were diagnosed as having breast cancer that patient obviously undergoes a CBE (Table 7).

Table 7: Reasons for not practicing BSE and CBE regularly

\section{Discussion}

Breast cancer is a significant health problem worldwide and the incidence rapidly increasing over the last two decades [6,7]. The basic knowledge of breast cancer such as diagnostic tools, screening techniques, risk factors, new approaches to prevention, early diagnosis play key roles in reducing mortality and morbidity rates [5].

This study was designed to evaluate the awareness about risk factors, early warning signs, screening methods for early detection, and treatment of breast cancer in a representative sample of Sri Lankan women. This study identified that the level of awareness about breast cancer screening methods among study population was low. Also the study showed inadequate knowledge about well-known risk factors for breast cancer among study population, in which only about $32 \%$ of participants had high knowledge 
and majority of them (about 43\%) had moderate and the remaining had low awareness levels. Age at menarche and infertility were the least frequently identified correctly as the risk factors for breast cancer in our study.

The present study revealed that the participants had inadequate knowledge about breast cancer early warning signs. When considering the awareness of the therapeutic methods, the results clearly indicated that knowledge levels among study population were low, in which only about $36 \%$ of them were in class with high levels of awareness. however they have shown poor knowledge, but slightly higher, about screening methods consistently about risk factors in developing as well as developed countries [8-12].

In contrast to present study, in a study reported that $26.7 \%$ of the study participants believed that mastectomy is the only treatment option and $54.9 \%$ had no any knowledge about therapeutic methods for breast cancer [13].

The most known sign and symptom regarding breast cancer in both groups was the lump or thickening in the breast. $\mathrm{MOH}$ is preferably a unit that is responsible for maintaining the preventive health care of the country while $\mathrm{NCH}$ is an institute responsible for curative health care. Majority of study participants in $\mathrm{MOH}$ clinics had poor knowledge about screening methods about MRI and FNAC screening methods. The low proportion of the respondents for MRI and FNAC can be attributed to not availability to this population particularly and more common applicability of those techniques for other diseases than breast examination. Majority of the observed differences about knowledge of all aspects of breast cancer can be attributed to specific sociocultural characteristics of studied populations. The most effective predictors of knowledge level about breast cancer risk factors, screening methods, early warning sign, and therapeutic modalities were educational qualification, personal history and contributing in educational and screening public programs, respectively.

Respondents identified the changes in size of breast or nipple as the least known sign (27.8 \%). Women exposed to risk factors were more vulnerable to breast cancers than who were not exposed [14]. In addition, Madduwa and Wijesinghe (2008) has revealed that $74.6 \%$ of respondents recorded breast lump as the most frequent sign of the breast cancer [6].

The educational qualification was the common significant predictor for high awareness levels. This is in agreement with previous studies in screening methodologies, risk factors, early warning signs and symptoms [15-19]. It is observed that a more highly significant association existed between higher educational qualification and awareness of therapeutic modalities. Although it is naturally expected that people having higher levels of education have more capability for obtaining more and effective information from various sources

Present study results in line with other previous studies showed a high awareness levels about screening methods [20-23], risk factors [24] and early warning sign [19]. The effective role of formal training programs and correct structured theoretical educations on breast cancer awareness and BSE training on improving of awareness levels [25]. However the consistent findings on the association of personal 
history or family history of with awareness about breast cancer reconfirm the importance of their predictive roles. it is expected that those educated and with a family or personal history of BS were particularly likely to acknowledge the potential various "controllable" risk factors [26]. Married and older people are generally more concerned about their health due to being more at risk for chronic disease and higher responsibilities toward the family, respectively. Therefore, they have more capability for obtaining more and effective information from various sources about health determinants.

In this study, the majority of the participants had practice of BSE. Similar to this study, $44 \%$ of the participants were aware of BSE in Tanzania 71.5\% and in India (55\%) had identified that BSE as an important technique in early diagnosis $[27,28]$. A previous study in Sri Lanka revealed that $35.7 \%$ of the population had heard of BSE [6]. However, only in Nigeria (19\%) and in India (8.9\%) of the participants practiced BSE monthly [29]. These studies reported that the awareness and practice of BSE are higher than those in the rural setting. Furthermore, this study also showed lack of knowledge on breast cancer to be the main challenge in breast cancer screening. The similarity in findings between these studies indicates that lack of knowledge in this matter is a problem in various African and Asian societies; therefore, more effort should be made to educate women in these areas.

Women who had higher level of education and who were engaging in professional jobs had a good knowledge about breast cancer. Awareness programs have to be established regarding health education about the BSE and CBE [30].

According to this study, knowledge regarding screening methods varied between two populations. Patients who already got breast cancer had a good knowledge when compared with other sample.

Women with family history of breast cancer have higher risk of developing the disease. Aging is a known risk factor and therefore post-menopausal women with a family history of breast cancer are a particularly vulnerable group. Lack of physical activity and obesity were identified as risk factors for developing breast cancer and they have an increased risk of developing post-menopausal breast cancer [31].

Family history of breast cancer, smoking history and the level of education were the strongest predictors of breast cancer among the study group. The time duration of usage of HRT was a risk factor for breast cancer. Other factors such as first full-term pregnancies before 30 years and high parity were found to be factors that protected against breast cancers [32].

The lack of knowledge and misbelieves about breast cancer prevention among females are responsible for the negative perception of the curability of the cancer which was detected early. The low level of knowledge and misbeliefs were also responsible for not believing the efficacy of the screening tests.

The study revealed that the low educated females had less number of screening attempts. poor educational level had affected the increased mortality rate of breast cancers in Asia. Majority of the participants had misconceptions on knowledge and screening of breast cancer. Comparatively family health nurses had a higher score than other category of public health nurses. 
The students who have had relatives affected with breast cancer had a better knowledge about the disease. This concluded that breast cancer awareness among school children should be enhanced [33].

Family history has no significant relationship with the practice of BSE for both samples, starting age of BSE for both samples and the frequency of practicing CBE for both samples. These findings suggest the urgent need of conducting health education programs to enhance knowledge and practice of early detection techniques

\section{Conclusions}

Present study revealed low levels of awareness regarding risk factors and signs and symptoms of breast cancers. However, the awareness of screening approaches was high among Sri Lankan adult women and indicated that higher educational attainments, attending screening and public educational programs and family history of breast cancer, had higher levels of awareness. These findings are important to implement new effective ways to overcome the burden of breast cancer disease among Sri Lankan women. Health educational sessions should be conducted for patients who had already been diagnosed as breast cancer patients, in order to improve knowledge and facilitate treatment options and finally to improve the quality of life.

\section{Abbreviations}

BSE: Breast Self-Examination; CBE: clinical Breast Examination; NCH: National Cancer Hospital; WHO: World health organization; WWC: Well Women clinics; MOH: Medical officers of Health; LKR: Sri Lankan Rupees; HRT: Hormone Replacement of Therapy; FNAC: Fine Needle Aspiration biopsy for Cytology; SPSS: Statistical Package for Social Science

\section{Declarations}

\section{Ethics approval and consent to participate}

Ethical clearance and approval was obtained from Ethics Review Committee, Faculty of Medicine, General Sir John Kotelawala Defence University. The permission to conduct the study was granted from the Regional Director of Health Services and from the Director of National Cancer Hospital, Sri Lanka. Written informed and verbal consent were taken from the participants individually prior to the interview conduction followed after the explanation of the aims and the benefits of the study. All parents were informed that their participation was voluntary and the procedure used did not pose any potential risk and their identities will be kept strictly confidential. Informed written consent forms were taken from all participants who voluntary participated and all information was kept in confidence.

\section{Consent to publish}

Not applicable. 


\section{Availability of data and materials}

\section{All data generated or analyzed during this study are included in this published article.}

\section{Competing interests}

The authors declare that they have no competing interests.

\section{Funding}

This research received no specific grant from any funding agency in the public, commercial or not-forprofit sectors.

\section{Author Contributions}

HSMSKW and KASJB conceived and designed the experiments. NDR, PMCD, CAKP, PWDNW, DMKNS and GAGMSA performed the study. LSG, NDR, PMCD, CAKP, PWDNW, DMKNS and GAGMSA involved to data interpretation and statistical analysis. LSG wrote the first draft of the manuscript. NDR, HSMSKW and KASJB critically revised the manuscript for intellectual content. All authors read and approved the final manuscript. HSMSKW, KASJB and LSG are guarantors of the paper.

\section{Acknowledgements}

We would like to express our deepest gratitude to the male and female individuals who participated in this study. It is our pleasure to thank the management, medical authorities and other health care workers in National Cancer Hospital, Sri Lanka ad MOH in Piliyandala for their cooperation for this study. Our sincere thanks also go to the academic and non- academic staff of the Department of Nursing and Midwifery, Faculty of Allied Health Sciences, Genera Sir John Kotelawala Defence University, Sri Lanka for their continuous support.

\section{References}

1. Montazeri A, Vahdaninia M, Harirchi I, Harirchi AM, Sajadian A, Khaleghi F, et al. Breast cancer in Iran: need for greater women awareness of warning signs and effective screening methods. Asia Pac Family Med. 2008;7:6.

2. National Comprehensive Cancer Network. NCCN clinical practice guidelines in oncology: breast cancer. Version 2. http://www.nccn.org/professionals/physician_gls/f_guidelines.asp.

3. McTiernan A. Behavioral risk factors in breast cancer: can risk be modified? Oncol. 2003;8:326-34.

4. Tsugane S. Dietary factor and cancer risk evidence from epidemiological studies. Cancer Chem. 2004;31:847-52. 
5. Elmore JG, Armstrong K, Lehman CD, Fletcher SW. Screening for breast cancer. J American Med Ass. 2005;293:1245-56.

6. Mudduwa L, Wijesinghe C. Awareness of breast cancer among females with breast diseases, Galle Med J. 2008;13:14-8.

7. Parkin DM, Bray F, Ferlay J, Pisani P. Global cancer statistics, 2002. CA: Cancer J Clin. 2005;55:74108.

8. Harirchi I, Kolahdoozan S, Karbakhsh M, Chegini N, Mohseni SM, Montazeri A, et al. Twenty years of breast cancer in Iran: downstaging without a formal screening program. Ann Oncol. 2011;22:93-7.

9. Taghavi A, Fazeli Z, Vahedi M, Baghestani AR, Pourhoseingholi A, Barzegar F, et al. Increased trend of breast cancer mortality in Iran. Asian Pac J Cancer Prev. 2012;13:367-70.

10. Alam AA. Knowledge of breast cancer and its risk and protective factors among women in Riyadh. Ann Saudi Med. 2006;26:272-7.

11. Al Junaibi RM, Khan SA. Knowledge and awareness of breast cancer among university female students in Muscat, sultanate of Oman-a pilot study. J Applied Pharma Sci. 2011;1:146-9.

12. Dandash KF, Al-Mohaimeed A. Knowledge, attitudes, and practices surrounding breast cancer and screening in female teachers of Buraidah, Saudi Arabia. Int J Health Sci. 2007;1:61-71.

13. Oyeka ICA, Ezeama MM. Breast cancer: information gap among female school teachers in Nigeria. Orient J Med. 1997;9:18-22.

14. Surdyka JA, Surdyka D, Stanislawek A, Staroslawska E, Patyra KI. Selected breast cancer risk factors and early detection of the neoplasm in women from Lublin region attending screening program in St. John's Cancer Center, years 2005-2006. Ann Agri Environ Med. 2014; 21:792-8.

15. Al-Dubai S, Qureshi AM, Saif-Ali R, Ganasegeran K, Alwan MR, Hadi JIS. Awareness and knowledge of breast cancer and mammography among a group of Malaysian women in Shah Alam. Asian Pac J Cancer Prev. 2011;12:2531-8.

16. Grunfeld EA, Ramirez AJ, Hunter MS, Richards MA. Women's knowledge and beliefs regarding breast cancer. British J Cancer. 2002;86:1373-8.

17. Linsell L, Burgess CC, Ramirez AJ. Breast cancer awareness among older women British J Cancer. 2008;99:1221-5.

18. Thomas EC. African American women's breast memories, cancer beliefs, and screening behaviors. Cancer Nur. 2004;27:295-302.

19. Budakoglu II, Maral I, Ozdemir A, Bumin MA. The effectiveness of training for breast cancer and breast self-examination in women aged 40 and over. J Cancer Edu. 2007;22:108-11.

20. Godazandeh GA, Khani H, Khalilian AR, Attard Z, Firozjaee MA, Partovi A, et al. Knowledge and practice of above 15 years old females towards breast cancer prevention in Sari township, 2004. J Mazandaran Uni Med Sci. 2006;16:64-76.

21. Jahan S, Al-Saigul AM, Abdelgadir MH. Breast cancer: knowledge, attitudes and practices of breast self-examination among women in Qassim region of Saudi Arabia. Saudi Med J. 2006;27:1737-41. 
22. Norman P, Brain K. An application of an extended health belief model to the prediction of breast selfexamination among women with a family history of breast cancer. British $\mathrm{J}$ Health Psychol. 2005;10:1-16.

23. Yelland MJ, Rice DE, Ward AE, Bain C, Siskind V, Schofield F. A profile of Australian women practicing breast self-examination. Asia Pac J Public Health. 1991;5:307-12.

24. Madanat $\mathrm{H}$, Merrill RM. Breast cancer risk-factor and screening awareness among women nurses and teachers in Amman, Jordan. Cancer Nur. 2002;25:276-82.

25. Mousavi SM, Montazeri A, Mohagheghi MA, Jarrahi AM, Harirchi I, Najafi M, et al. Breast cancer in Iran: an epidemiological review. Breast J. 2007;13:383-91.

26. Lykins ELB, Graue LO, Brechting EH, Roach AR, Gochett CG, Andrykowski MA. Beliefs about cancer causation and prevention as a function of personal and family history of cancer: a national, population-based study. Psycho-Oncol. 2008;17:967-74.

27. Ng'ida FD, Kotoroi GL, Mwangi R, Mabelele MM, Kitau J, Mahande MJ. Knowledge and practices on breast cancer detection and associated challenges among women aged 35 years and above in Tanzania: a case in Morogoro Rural District. Breast Cancer. 2019;11:191-7.

28. Sehrawat JS, Mor S. Knowledge, beliefs and practices about breast cancer and its self-examination procedure among urban and rural women of district Gurdaspur, Punjab, India: a cross sectional study. Int J Community Med Public Health. 2017;4:120-8.

29. Gwarzo UMD, Sabitu K, Idris SH. Knowledge and practice of breast-self-examination among female undergraduate students of Ahmafu Bello University Zaria, Northwestern Nigeria. Ann Afr Med. 2009;8:55-8.

30. Okobia MN, Bunker $\mathrm{CH}$, Okonofua FE, Osime U. Knowledge, attitude and practice of Nigerian women towards breast cancer: A cross-sectional study. World J Surgical Oncol. 2006;4:11.

31. Begum P, Richardson CE, Carmichael AR. Obesity in post-menopausal women with a family history of breast cancer: prevalence and risk awareness. Int Seminars Surg Oncol. 2009;6:1- 5.

32. Sezer H, Yilmaz M, Gurler H, Koyuncu A. Breast cancer risk factors in Turkey: a hospital-based casecontrol study. Asian Pac J Cancer Prev. 2011;12:2317-22.

33. Ranasinghe HM, Ranasinghe N, Rodrigo C, Seneviratne RDA, Rajapakse S. Awareness of breast cancer among adolescent girls in Colombo, Sri Lanka: a school based study, BMC Public Health 2013;13:1209.

\section{Tables}


Table 1. Socio demographic characteristics of study participants

\begin{tabular}{llrr}
\hline Variables & Categories & \multicolumn{2}{c}{ No. of participants (\%) } \\
\hline Age (Years) & $30-40$ & $216(68.1)$ & \multicolumn{1}{c}{ NCH } \\
\hline & $41-50$ & $44(13.9)$ & $82(25.9)$ \\
\hline & $51-60$ & $36(11.3)$ & $97(30.6)$ \\
\hline Educational level & No formal education & $33(10.4)$ & $16(4)$ \\
\hline & Primary education & $73(23)$ & $122(38.5)$ \\
\hline & Secondary education & $130(41)$ & $141(44.5)$ \\
\hline Marital status & Tertiary education & $81(25.6)$ & $38(12)$ \\
\hline Single & $16(5)$ & $32(10.1)$ \\
\hline No of children & Married & $301(95)$ & $285(89.9)$ \\
\hline & 0 & $68(21.5)$ & $44(13.9)$ \\
\hline Breast Feed & Yes -8 & $241(76)$ & $246(77.6)$ \\
\hline Family History of & Yes & $8(2.5)$ & $27(8.5)$ \\
\hline breast cancer & No & $244(77)$ & $267(84.2)$ \\
\hline
\end{tabular}


'able 2. Awareness regarding signs and symptoms and risk factors of breast cancer

ariables

No. of positive

responses (\%)

$\mathrm{MOH}$

$\mathrm{NCH}$

$\mathrm{p}$

value

igns and Symptoms

iedness of breast skin

$113(35.6) \quad 181(57.1) \quad<$

'hange in the position of nipple

$144(45.4) \quad 223(70.3) \quad<$

'ulling in the nipple

115 (36.3) $228(71.9)<$

ischarges or bleeding from nipple

$202(63.7) \quad 238(75.1) \quad 0.002$

Jipple rash

$109(34.4) 168(53.0) \quad<$

'hanges in the size of the breast / nipple

$88(27.4) \quad 188(59.3)$

0.001

'hanges in the shape of the breast / nipple

$143(45.1) \quad 214(67.5)$

0.001

ump or thickening of breast

$252(79.5) \quad 296(93.4)$

0.001

'ain in the breast or arm pit

$143(45.1) \quad 217(68.5)$

0.001

0.001

\section{isk factors}

Iaving a past history of breast cancer

$187(59.0) \quad 241(76.0)$

0.001

Ising hormone replacement therapy (HRT)

$89(21.1) \quad 160(50.5)$

0.001

:onsumption of alcohol and other drugs

$148(46.7) \quad 188(59.3) \quad 0.001$

ieing overweight $(\mathrm{BMI}>23)$

$91(28.7) \quad 144(45.4)$

0.001

Iaving a close relative diagnosed with a breast cancer

$163(51.4) \quad 240(75.7)$

Iaving children in later age or not at all

$116(36.6) \quad 167(52.7)$

0.001

tart menarche at early age

$49(15.5) \quad 116(36.6)$

0.001

Iaving a late menopause

99 (31.2) 170 (53.6)

0.001 


\begin{tabular}{|c|c|c|c|}
\hline & & & 0.001 \\
\hline $\begin{array}{l}\text { Iaving a less activity level ( }<30 \text { minutes, } 5 \text { times a } \\
\text { reek exercise) }\end{array}$ & $87(27.4)$ & $133(42.0)$ & $\begin{array}{r}< \\
0.001\end{array}$ \\
\hline tress and depression & $121(38.2)$ & $214(67.5)$ & $\begin{array}{r}< \\
0.001\end{array}$ \\
\hline
\end{tabular}


Table 3. Awareness of signs and symptoms and risk factors with socio demographic characteristics

Signs and symptoms (Range $0 \quad$ Risk factors (Range 0 - 10) - 9)

\begin{tabular}{|c|c|c|c|c|c|c|c|c|c|}
\hline Variable & Category & $\mathrm{MOH}$ & $\begin{array}{c}\mathrm{p} \\
\text { value }\end{array}$ & $\mathrm{NCH}$ & $\begin{array}{c}\mathrm{p} \\
\text { value }\end{array}$ & $\mathrm{MOH}$ & $\begin{array}{c}\mathrm{p} \\
\text { value }\end{array}$ & $\mathrm{NCH}$ & $\begin{array}{c}\mathrm{p} \\
\text { value }\end{array}$ \\
\hline & & $\begin{array}{r}\text { Mean } \\
(\mathrm{SD})\end{array}$ & & $\begin{array}{r}\text { Mean } \\
(\mathrm{SD})\end{array}$ & & $\begin{array}{r}\text { Mean } \\
(\mathrm{SD})\end{array}$ & & $\begin{array}{r}\text { Mean } \\
(\mathrm{SD})\end{array}$ & \\
\hline \multirow{8}{*}{$\begin{array}{l}\text { Age } \\
\text { (Years) }\end{array}$} & $31-40$ & 4.00 & 0.170 & 6.57 & 0.021 & 3.31 & 0.014 & 5.70 & 0.239 \\
\hline & & $(2.61)$ & & $(2.29)$ & & $(2.47)$ & & (2.33) & \\
\hline & $41-50$ & 4.82 & & 6.65 & & 4.36 & & 6.05 & \\
\hline & & (2.18) & & $(2.47)$ & & $(2.66)$ & & $(2.42)$ & \\
\hline & $51-60$ & 4.03 & & 6.22 & & 4.00 & & 5.52 & \\
\hline & & $(2.66)$ & & $(2.61)$ & & $(2.66)$ & & $(2.95)$ & \\
\hline & $61-70$ & 4.71 & & 5.56 & & 4.38 & & 5.25 & \\
\hline & & $(1.73)$ & & $(2.46)$ & & $(2.33)$ & & (2.67) & \\
\hline \multirow{8}{*}{$\begin{array}{l}\text { Education } \\
\text { level }\end{array}$} & No formal & 4.82 & 0.083 & 4.37 & 0.005 & 3.31 & 0.011 & 5.13 & 0.090 \\
\hline & education & $(2.82)$ & & (3.13) & & $(2.47)$ & & (3.18) & \\
\hline & Primary & 4.11 & & 5.93 & & 4.36 & & 5.19 & \\
\hline & education & $(2.52)$ & & $(2.62)$ & & $(2.66)$ & & $(2.71)$ & \\
\hline & Secondary & 4.37 & & 6.39 & & 4.00 & & 5.82 & \\
\hline & education & $(2.38)$ & & $(2.27)$ & & $(2.66)$ & & $(2.49)$ & \\
\hline & Tertiary & 3.65 & & 6.82 & & 4.38 & & 6.24 & \\
\hline & education & $(2.36)$ & & $(2.45)$ & & $(2.33)$ & & $(2.81)$ & \\
\hline \multirow{4}{*}{$\begin{array}{l}\text { Marital } \\
\text { state }\end{array}$} & Single & 4.56 & 0.520 & 6.03 & 0.760 & 4.00 & 0.496 & 6.03 & 0.325 \\
\hline & & $(2.27)$ & & $(2.20)$ & & $(2.50)$ & & (2.87) & \\
\hline & Married & 4.15 & & 6.18 & & 3.58 & & 5.54 & \\
\hline & & $(2.48)$ & & $(2.55)$ & & $(2.39)$ & & $(2.64)$ & \\
\hline \multirow{4}{*}{$\begin{array}{l}\text { Breast } \\
\text { feeding }\end{array}$} & Yes & 4.09 & 0.298 & 6.22 & 0.359 & 3.75 & 0.039 & 5.58 & 0.931 \\
\hline & & $(2.54)$ & & $(2.56)$ & & $(2.41)$ & & (2.67) & \\
\hline & No & 4.44 & & 5.86 & & 3.10 & & 5.62 & \\
\hline & & $(2.23)$ & & $(2.26)$ & & $(2.86)$ & & $(2.68)$ & \\
\hline \multirow{4}{*}{$\begin{array}{l}\text { family } \\
\text { history }\end{array}$} & Yes & 4.04 & 0.779 & 6.26 & 0.694 & 4.80 & 0.009 & 6.00 & 0.139 \\
\hline & & $(2.57)$ & & $(2.42)$ & & $(2.61)$ & & $(2.63)$ & \\
\hline & No & 4.18 & & 6.13 & & 3.50 & & 5.47 & \\
\hline & & $(2.47)$ & & $(2.55)$ & & $(2.35)$ & & (2.67) & \\
\hline \multirow{3}{*}{$\begin{array}{l}\text { No. of } \\
\text { children }\end{array}$} & 0 & 4.34 & 0.027 & 5.55 & 0.202 & 3.16 & 0.078 & 5.55 & 0.867 \\
\hline & & $(2.24)$ & & $(2.47)$ & & $(2.32)$ & & $(2.80)$ & \\
\hline & $1-3$ & 4.05 & & 6.24 & & 3.76 & & 5.57 & \\
\hline
\end{tabular}




$\begin{array}{rrrrr} & (2.51) & (2.57) & (2.39) & (2.70) \\ 4-8 & 6.38 & 6.44 & 2.50 & 5.85 \\ & (2.38) & (2.00) & (2.56) & (2.17)\end{array}$

Table 4. The knowledge regarding screening methods

\begin{tabular}{lccr}
\hline Screening methods & No. of positive responses (\%) & \\
\cline { 5 - 5 } & MOH & NCH & p value \\
\hline Breast self-examination & $254(80.1)$ & $265(83.6)$ & 0.257 \\
\hline Clinical breast examination & $249(78.5)$ & $291(91.8)$ & $<0.001$ \\
\hline Mammography & $104(32.8)$ & $284(89.6)$ & $<0.001$ \\
\hline MRI & $109(34.4)$ & $199(62.8)$ & $<0.001$ \\
\hline FNAC & $120(38.0)$ & $264(83.3)$ & $<0.001$ \\
\hline
\end{tabular}


Page 20/24 
Table 5. Practices of early detection methods for breast cancer

\begin{tabular}{llrrr} 
Practices & Responses & \multicolumn{2}{l}{ No. of participants (\%) } & \\
& & MOH & NCH & p value \\
\hline Practice of BSE & & $\mathbf{( n = 1 3 8 )}$ & $\mathbf{( n = 1 8 8 )}$ & \\
\hline Frequency of BSE & Once a month & $74(53.6)$ & $119(63.3)$ & 0.098 \\
\hline & Once in three months & $12(8.7)$ & $12(6.4)$ & \\
& Once in quarter of a year & $12(8.7)$ & $6(3.2)$ & \\
& Not very often & $40(29.0)$ & $51(27.1)$ & \\
\hline Age when first BSE started & <30 years & $55(39.9)$ & $23(12.2)$ & $<0.001$ \\
\hline & 30 - 35 years & $56(40.6)$ & $28(14.9)$ & \\
\hline & >35 years & $27(19.6)$ & $137(72.9)$ & \\
\hline Level of education & No formal education & $12(8.7)$ & $7(3.7)$ & $<0.001$ \\
\hline & Primary level & $22(15.9)$ & $61(32.4)$ & \\
\hline & Secondary level & $56(40.6)$ & $94(50.0)$ & \\
\hline Family history of BSE & Tertiary level & $48(34.8)$ & $26(13.8)$ & \\
\hline & Yes & $14(10.1)$ & $39(20.7)$ & 0.010 \\
\hline & No & $124(89.9)$ & $149(79.3)$ &
\end{tabular}

Practice of CBE

Frequency of $\mathrm{CBE}$

\begin{tabular}{l}
\hline Level of education \\
\hline Family history and CBE \\
\hline Knowledge of Mammography
\end{tabular}

Recommended age to start at the age of 30

mammography examination at 35

(Years)
Once

1-3 times

3-5 times

More than 5 times

No formal education

Primary level

Secondary level

Tertiary level

Yes

No

at 40

at 45

Don't know

\begin{tabular}{rrr}
$(\mathbf{n}=108)$ & $(\mathbf{n}=\mathbf{3 1 7})$ & \\
$100(92.6)$ & $195(61.5)$ & $<0.001$ \\
$1(0.9)$ & $38(12.0)$ & \\
\hline $5(4.6)$ & $40(12.6)$ & \\
$2(1.9)$ & $44(13.9)$ & \\
$8(7.4)$ & $16(5.0)$ & $<0.001$ \\
$22(20.4)$ & $122(38.5)$ & \\
$46(42.6)$ & $141(44.5)$ & \\
$32(29.6)$ & $38(12.0)$ & \\
\hline $12(11.1)$ & $72(22.7)$ & $<0.001$ \\
\hline $96(88.9)$ & $245(77.3)$ &
\end{tabular}

( $\mathrm{n}=317) \quad(\mathrm{n}=317)$

$38(12.0) \quad 58(18.3)<0.001$

$95(30.0) \quad 69(21.8)$

25 (7.9) 55 (17.4)

$4(1.3) \quad 5(1.6)$

155 (48.9) 130 (41.0) 
Page 22/24 
Table 6. Attitudes regarding breast cancer

\begin{tabular}{|c|c|c|c|c|}
\hline \multirow[t]{2}{*}{ Attitudes } & \multirow[t]{2}{*}{ Responses } & \multicolumn{3}{|c|}{$\begin{array}{l}\text { No. of positive responses } \\
\qquad(\%)\end{array}$} \\
\hline & & $\mathrm{MOH}$ & $\mathrm{NCH}$ & $\mathrm{p}$ value \\
\hline \multirow[t]{5}{*}{ If a breast cancer developed } & will be scared & $\begin{array}{r}200 \\
(63.1)\end{array}$ & $\begin{array}{r}193 \\
(60.9)\end{array}$ & 0.567 \\
\hline & will consult a doctor & $\begin{array}{r}313 \\
(98.7)\end{array}$ & $\begin{array}{r}311 \\
(98.1)\end{array}$ & 0.524 \\
\hline & $\begin{array}{l}\text { will use traditional } \\
\text { medicine }\end{array}$ & $\begin{array}{r}38 \\
(12.0)\end{array}$ & $25(7.9)$ & 0.245 \\
\hline & will go to prayer house & $\begin{array}{r}207 \\
(65.3)\end{array}$ & $\begin{array}{r}258 \\
(81.4)\end{array}$ & $<0.001$ \\
\hline & $\begin{array}{l}\text { will agree to perform } \\
\text { mastectomy }\end{array}$ & $\begin{array}{r}254 \\
(80.1)\end{array}$ & $\begin{array}{r}305 \\
(96.2)\end{array}$ & $<0.001$ \\
\hline $\begin{array}{l}\text { Occurrence of breast cancer in } \\
\text { old age }\end{array}$ & Yes & $\begin{array}{r}80 \\
(25.2)\end{array}$ & $\begin{array}{r}103 \\
(32.5)\end{array}$ & 0.044 \\
\hline Breast cancer is curable & Yes & $\begin{array}{r}248 \\
(78.2)\end{array}$ & $\begin{array}{r}262 \\
(82.6)\end{array}$ & 0.161 \\
\hline $\begin{array}{l}\text { Survival of more than five } \\
\text { years }\end{array}$ & Yes & $\begin{array}{r}103 \\
(32.5)\end{array}$ & $\begin{array}{r}109 \\
(34.4)\end{array}$ & 0.613 \\
\hline $\begin{array}{l}\text { Willingness to allow a male } \\
\text { doctor }\end{array}$ & Yes & $\begin{array}{r}305 \\
(96.2)\end{array}$ & $\begin{array}{r}312 \\
(98.4)\end{array}$ & 0.085 \\
\hline
\end{tabular}


Table 7: Reasons for not practicing BSE and CBE regularly Reasons for the negligence in BSE and No. of participants (\%)

\begin{tabular}{lrr} 
CBE practice & MOH & \multicolumn{1}{c}{ NCH } \\
\hline Breast self-examination (BSE) & & \\
\hline I don't have breast problem & $133(54.7)$ & $61(30.8)$ \\
\hline I don't think I should & $62(25.5)$ & $50(25.3)$ \\
\hline I don't feel comfortable doing this & $8(3.3)$ & $17(8.6)$ \\
\hline I don't know how to do that & $53(21.8)$ & $50(25.3)$ \\
\hline Carelessness & $79(32.5)$ & $103(52.0)$ \\
\hline Too frequent to practice & $18(7.4)$ & $21(10.6)$ \\
\hline I don't think it is necessary & $80(32.9)$ & $42(21.2)$ \\
\hline Unsure about benefits & $21(8.6)$ & $13(6.6)$ \\
\hline Others & $47(19.3)$ & $33(16.7)$
\end{tabular}

\section{Clinical breast examination (CBE)}

Concern about extra money $13(6.2)$

Concern about extra time $27(12.9)$

Fear of outcome $6(2.9)$

Too young to participate $22(10.5)$

No signs and symptoms of breast cancer 135 (64.6)

No one recommended

$61(29.2)$

Unsure about the benefits

Others

55 (26.3) 